\title{
A Review of Nature-Based Algorithms Applications in Green Supply Chain Problems
}

\author{
A. Sadrnia, H. R. Soltani, N. Zulkifli, N. Ismail, and M. K. A. Ariffin
}

\begin{abstract}
In the recent years, there is a significant attention among researchers and practitioners to environmental issues and green supply chain (GrSC) because of legislations and profit oriented motivations.Because of considering environmental issues GrSC besides the economic variables, the models are very difficult to find optimal. Hence, complicated green problems call for development of modern optimization methods and algorithms to solve optimization models by efficient techniques. In recent decades, meta-heuristic algorithms have been developed to overcome the problem that most of them are inspired from nature. Some of the algorithms have been inspired from natural generation, some of them inspired from swarm behavior, and others simulate natural processes. In this research we summarize the recent advance evolutionary optimization algorithms and swarm intelligence algorithms which are applied to GrSC and green logistics. Literature reviewed in this paper shows the current state of the art and discusses the potential future research trends.
\end{abstract}

Index Terms-Evolutionary algorithms, green supply chain, meta-heuristic, swarm intelligence algorithms.

\section{INTRODUCTION}

These days government and people are more cautions and careful with the environment and concerned about climate change such that businesses are taking an increasing active on in society [1]. Literature surveys show that after the quality revolution of the 1980s and the supply chain revolution of the 1990s, Green Supply Chain (GrSC) has been averted by researchers and scientists [2]. Thus, The supply chain concept has been changed by environmental concerns so that, not only is an efficient supply chain based on economic conditions, but also interest is growing in integrating environmental issues into the entire supply chain such that they are more "green" and produce zero waste. Wide range of activities has to be implemented while supply chains are being green. Green manufacturing, reverse logistics networks, emission reduction in logistics network, closed-loop supply chain, disassembling, remanufacturing, and waste management, and reducing raw material are some of initiatives belongs of green supply chain ( $\mathrm{GrSC}$ ) concept.

The implementation of greening supply chain and logistics networks involves a wide range of design, planning, and control optimization problems. Various mathematical modeling approaches such as Mixed Integer Linear Programming (MILP) [3]-[5], Mixed Integer Non-Linear

Manuscript received April 10, 2013; revised July 23, 2013. This work was supported support from Ministry of Science, Technology and innovation of Malaysia under Research Project No. 5527085.

The authors are with the Department of Mechanical and Manufacturing Engineering, Faculty of Engineering, University Putra Malaysia, Serdang, Selangor, Malaysia (e-mail: hsadrnia@yahoo.com)
Programming (MINLP) [6], Continuous Approximation (CA) [7], System Dynamic Modeling (SDM) [8]-[10] and Fuzzy Goal Programming (FGP) [11] have been used by researchers to design mathematical modeling GrSC problems. Recently, with regards to literatures in most of cases considering environmental constraints, parameters and variables along with economic issues to supply chain leads to complex models. In this situation the coordination between all aspects across the supply chain is more difficult in comparison with the traditional supply chains. This is because most of such problems are nonlinear, non-convex or maybe has multiple local optima. In addition to wide range activity that should be considered in GrSC the consideration of supply chain design with multi-objective optimization (generally incompatible objectives) is a new trend worthy of study and it causes more complicity in the models to be solved.

Since most of these models belong to the class of NP-hard problems [12] they cannot be successfully analyzed by analytical models. More ever, exact and traditional techniques such as Branch-and-Bound ( $\mathrm{B} \& \mathrm{~B})$ and $\varepsilon$-constrain either cannot solve the models or computational requirements increase tremendously as models become more realistic [13]. In the few decades, researchers have tried to develop various approximate algorithms and modern heuristic algorithm to escape the problem. Heuristics and meta-heuristics as approximate algorithms seek to obtain acceptable near-optimal solutions and require low computation requirements and time. They work based on stochastic search methods are inspired from nature processes or animal swarm behavior. These techniques can help researchers to overcome the complexity issues in GrSC[14] and have gained popularity in the optimization of grass problems because usually they use a collection of agents (like ants or honey bees) and perform a parallel search with multiple starting points in solution space. It is noticeable that meta-heuristic algorithm may solve some problems better and some problems worse than other methods [15], [16] so that researchers should select proper algorithms regarding to the problem characteristics, available time to implementation of the model, computational requirement, and required solution quality.

Naturally inspired meta-heuristic optimization techniques are divided into two main categories (although there are minor other sub-branches): (i) evolutionary algorithms and (ii) algorithms based on swarm intelligence .In this research, we introduce briefly evolutionary and swarm intelligence algorithms and review particularly the latest researches in their applications in field of GrSC, reverse logistics, closed-loop supply chain, green logistics and logistics network design. 


\section{SWARM BASED AlgORITHMS}

Swarming has been defined "distributed problem solving devices inspired by the collective behavior of social insect colonies and other animal societies." Swarm intelligence (SI) is a relatively novel field of nature-inspired algorithms for multi-agent search and optimization. It refers to the study of the plural behaviors of systems that are made of many components. They usually use decentralized controls to coordinate and self-organization. The behaviors of a single animal such as ant, bee, termite, fish, or wasp often are too simple, but their swarm and social behavior is superior matter like smart population. A group of three fish behaves as if none of the fish are leading, but rather each fish has an influence on the whole and the global pattern is often advantageous to the organisms; let it be avoided predators, maximizing food collection or aiding the mating process and reproduction [17]. Few examples of nature swarming are tabulated regarding to Table I. Historically, Beni and Wang excogitated the phrase Swarm Intelligence in the late 1980s in the context of cellular robotics. SI systems are typically made up of a population of simple agents that everyone interact locally with another and with their environment [18]. In SI there is no centralized control unit to dictate how individual agents should behave; but local interactions between such agents often lead to the emergence of global behavior and match their position or speed with regards to the new situations.

TABLE I: SOME EXAMPLES OF SWARMING IN NATURE.

\begin{tabular}{cc}
\hline Swarming Behavior & Entities \\
\hline Flocking & Birds \\
Prev Surrounding & Wolves \\
Schooling & Fish \\
Web construction & Spiders \\
Synchronization & Fireflies \\
Feeding aggregation & Bark beetles \\
Hive Construction & Bees, Wasps, Hornets, Termites \\
Task allocation & Wasps \\
Thermo regulation & Bees \\
Food source selection & Ants, Bees \\
Cooperative transport & Ants \\
Nest sorting & Ants \\
Pattern generation & Bacteria, Slime Mold \\
Path formatting & Ants \\
Law of gravity & Mass interactions \\
Echolocation & Bat \\
Brooding & Cuckoo \\
Mammalian adaptive & Immune systems \\
Herding behavior & Krill individuals \\
Path optimizing & Natural rivers \\
\hline & \\
\hline &
\end{tabular}

SI algorithms are inspired by collective behaviors observed in natural systems included animal behavior or other natural processes such as the law of gravity or immune system. The foraging behavior of ants as in ant colony optimization (ACO) [13], [19], [20], the choreography of bird flocks as in the partial swarm optimization (PSO) [21], the intelligent behavior of honey bee swarms as in an artificial bee colony (ABC) [22], [23] are examples that inspired from animal collective life. In addition, the gravitational search algorithm (GSA) [15], [24] is based on the mass interactions and the law of gravity, Krill herd algorithm (KHA) [25] is inspired from herding behavior of krill individuals, and Intelligent water drops (IWD) [26] are simulated natural rivers and how they find almost optimal paths to their destination. Onthe rest of paper the first-fourth algorithms as most popular will be explained and reviewed their application in GrSC.

\section{A. Particle Swarm Optimization}

Particle swarm optimization (PSO) is one of the swarm-based global optimization algorithms that can move particles (as solutions) through feasible problem space to find the new optimum solutions. Initially, PSO inspired from flocks of birds, schools of fish, and even human social behavior. The nature-based meta-heuristic algorithm was proposed by Kennedy and Eberhart[21], [27]. They simulated a group of birds that are looking for food within some area and they don't know food location. Kennedy and Eberhart[21] treated each single solution of the optimization problem as a "bird" that flies through the search space. They call each single solution at "particle". Each particle is characterized by the fitness value, current position in the space and the current velocity [28], [29]. When flying through the solution space all particles try to follow the current optimal particles. A position vector and a velocity are nominated to each particle and they are adjusted in any iteration with regards to local and global best found in the whole swarm. In optimization science, PSO is computational algorithm that tries to improve a candidate feasible solution with attention to a given amount of quality. Then, move these particles around the search space regarding the candidate's solution's position and velocity.

Zhu et al. [30] developed the PSO search strategy for the vehicle routing traveling time problem that it can use to air pollution reduction in forwards and reverse logistics. In the research PSO has been tested on a few numerical examples and they compared the obtained results with genetic algorithm. They concluded the developed PSO algorithm got the optimal solutions much faster than the genetic algorithm (GA) algorithm due to it is a swarm-based algorithm. Similarly Moghaddam et al. [31] used PSO to solve the model to overcome uncertainly in vehicle routing planning. Nan et al. [32] used PSO to solve reverse logistics location of remanufacturing factory, and the distribution of goods is solved by the PSO algorithm to minimize cost. The optimal solution of the model is obtained by developed PSO and traditional PSO, which reduces the calculation complexity, selects the reverse logistics remanufacturing factory efficiently. In the field of reverse logistics network optimization another study has been done by Yanchao et al. [33]. Their study was established a reverse logistics network multi-objective optimization model that considered environment effect and the waste recycling factors, such as locations of facilities and frequency transportations. Then they improved PSO by adopting the grouping and the cataclysm theory and solved the complex model. In another case, Kannan et al. [34] used PSO to minimize cost and environment effect in closed-loop logistics network and compared the result with GA. These Empirical studies have shown that PSO has a high efficiency in convergence to desirable optima and performs on many GrSC complex problems. Since most green problems are belonging of 
multi-objective optimization, PSO can be employed in particular problems.

Although in multinomial function particle populations will quickly lose diversity and PSO will cause premature convergence and trap to local front rather than global ones [35]-[37], some researchers proposed some operators (like crossover) or hybridize by other algorithm to overcome partly the problem [35], [38]-[40]. Liu et al. [38] and Masrom et al. [39] hybridized PSO and GA to solve vehicle routing problem as a nonlinear transportation problem which the final algorithms can be used for logistics network optimization in GrSC problems.

\section{B. Ant Colony Optimization}

Ant colony optimization that is a probabilistic technique to solve complex problems is initially proposed by Dorigo in 1992 [19], [41]. ACO that can reduce finding best and shortest paths through the graphs is based on ant behavior for seeking a path to achieve the source of food. This is achieved by a substance called pheromone that shows the trace of an ant [42] that permit them to communicate to each other. To find the best way to food, ant employs heuristic information. They leave the nest and move randomly to find food but when they find a pheromone trail that made by other ants, they decide whether or not to follow it. If they decide to follow it they make own pheromones over the trail. Quality of pheromone in a path makes more chance to the path to be selected by ant over the other paths and gradually the amount of pheromone on the path would be highlighted among the others. ACO is a simulation of the colony of ant to find the shortest path as in the Fig. 1 is shown.

In the ACO algorithm, the nest is represented by initial condition and terminal condition play as the food. The ant moves in a network that the pheromones are deposited over vertices or edges. The ants choose a node on the network for the next steps based on a probabilistic decision that quantity of pheromone deposited over the node or edge can affect on the function for decision. The problem is represented by a set of constraints that every time an ant selects a vertex or edge, it has to evaluate the set of constraint [43].

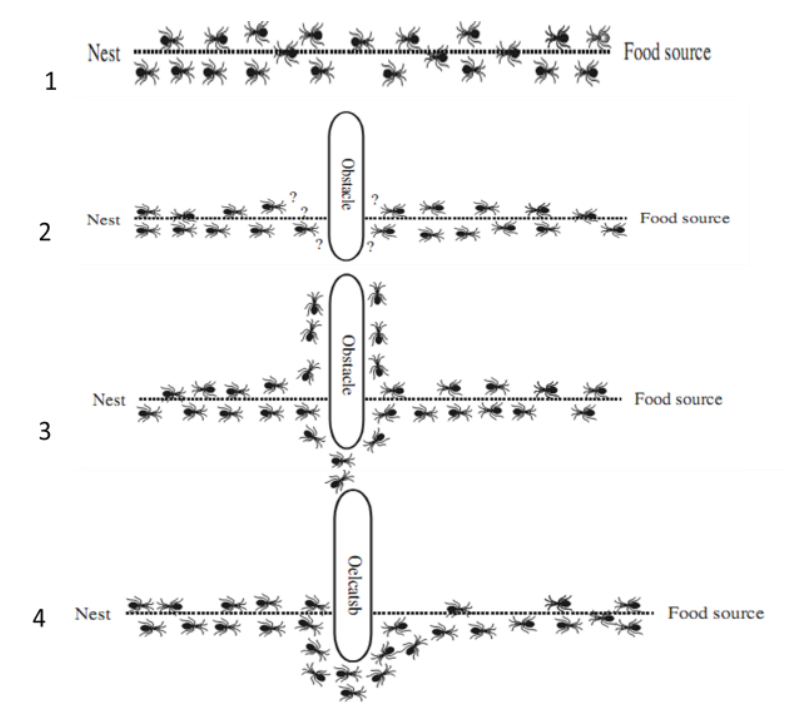

Fig. 1. Ants' behavior to find food: (1) ants walk along the shortest path, (2) ants have to choose one of the two available paths that have been made by obstacle, (3) ants find available paths and (4) the ants discover the new shortest path characterized.
One of the first applications of ACO in GrSC refers to McGovern et alhave studied in 2006 [44]. They implemented ACO to minimize the number of remanufacturing work stations, minimize idle time, and balances product disassembly line in recycling and remanufacturing systems. They emphasized ACO is used to provide a feasible solution very fast, near-optimal solution to the multiple objective for that particular problem. In the same light, Ding et al. [45] used ACO to solve multi objective optimization for minimizing the use of precious resources and maximizing the level of process capability in the disassembly process. Some researcher, the ACO has been employed to minimize vehicle rout in case of time and number of travels that it can minimize fossil fuel consumption and air pollution [46], [47]. And also, wastes collection facility location model has been developed by Bautista et al. [48] to minimize collection cost using ACO as solution method. Regarding to the capability of ACO to solve complex problems it seems the use of ACO techniques in GrSC design is yet in a fetal stage [49].

\section{Artificial Bee Colony}

Artificial bee colony (ABC) is a swarm-based meta-heuristic algorithm that introduced in 2005 by Karaboga [50] and open a new direction in the field of optimization algorithms in complex problems. Similar to PSO and ACO which are inspired from bird's life and ant colony social life, $\mathrm{ABC}$ is an algorithm inspired from bee colonies behavior in the nature. The ABC's function according to the bee's life in the nature can be explained as follows. Initially each bee explores the food individually and when a bee finds the food start dancing to inform other bees in the colonies. Other bees collect food and bring to the hive and then they can do one of the follow actions [51]:

1) Abandon the previous food source and become again uncommitted follower.

2) Continue to forage at the food source without recruiting the nest mates.

3) Dance and thus recruit the nest mates before the return to the food source.

With a certain probability that is dependent on the obtained feed quality, its distance from the hive and the number of the bees which are now engaged with this feed resource, a bee selects one of the stated actions and follows its work in a similar repetitive form [51]. This behavior can be applied to many complicated engineering problems including computational, control, optimization, transportation, etc.

Recently, regarding to $\mathrm{ABC}$ capabilities to solve complex problems scholars the algorithm has been interested inimplementing it in green problems. For instance, Vishwa et al. [52] used ABC to solve complex closed-loop logistics problem with return rates uncertainly. They concluded $A B C$ algorithm has been implemented successfully and solution quality and convergence rate are significantly outperformed rather than PSO in their case study. In the same light, in 2012 Xing et al. [53] implemented $\mathrm{ABC}$ algorithm to optimize e-remanufacturing. They argued the simulation results showed that the proposed algorithm performance is satisfactory. In 2008, Banerjee et al. developed ABC and proposed the Pareto artificial bee colony (PABC) to solve multi-objective optimization [54]. With regards to in the most gross problems should be considered economic and 
environmental objectives then the PABC can be used as an efficient algorithm in these kinds of problems.

\section{Gravitational Search Algorithm}

One of the novel meta-heuristic stochastic optimization algorithm inspired by the law of gravity and mass interactions is Gravitational Search Algorithm [15]. GSA, the individuals, called agents, is the collection of masses which interact with each other based on the Newtonian gravity and the laws of motion. The agents share information using the gravitational force to guide the search toward the best location in the search space. At GSA, search agents are the collection of masses. All these objects attract one another by gravitational force, and this force causes a global movement of all objects toward the objects with heavier masses as Fig. 2 is shown. Hence, masses cooperate using a direct form of communication, through gravitational force. The heavy masses that correspond to good solutions move more slowly than lighter masses, which guarantee the exploitation step of the algorithm. Each agent has position, inertial mass, active gravitational mass, and passive gravitational mass. The position of the mass corresponds to a solution of the problem, and its gravitational and inertial masses are determined using a fitness function. By changing the velocities over time, the agents are likely to move toward the global optima.

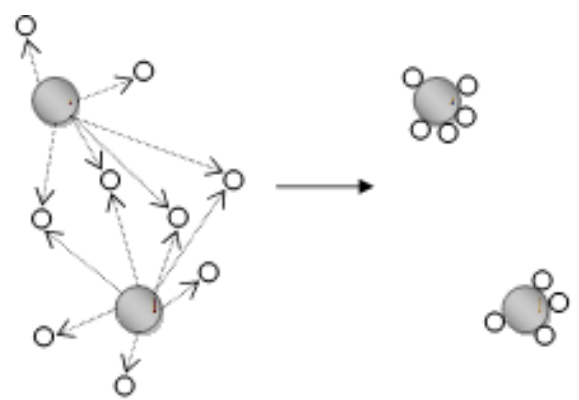

Fig. 2. Each mass accelerates toward the result force that acts it from the other masses.

Results of experiments undertaken previously show the high performance and the global search ability of GSA in solving various nonlinear functions comparing PSO [15], [55]. The superior solution and convergence rate cause GSA have been interested by researchers to be supply chain problems. In 2012, Sadrnia et al. [56] used GSA as a new solving technique to find optimal solutions in recycling automotive alternators close-loop logistics in end-of-life. They assumed all material and product flows between facilities in closed-loop supply chain such as suppliers, manufacturer, distributors, retailers, collection centers, and recycling centers as object with some respective masses. They compared the result with GA and expressed GSA tends to find the global optimum faster than GA; hence, it has a higher convergence rate. GSA also has been implemented recently to find out the optimum strategy in demand managing [57]. In the research, the authors argued GSA advantages to solve supply chain problems.

\section{EVOLUTIONARY AlGORITHMS}

Another category of nature-based meta-heuristic algorithms are Evolutionary algorithms (EA). EAs are population search methods that are inspired by biological evolution, which leads to producing better and better approximations to a solution. In other words, the basic idea of evolutionary algorithms is to "select best, discard the rest." This means that better solutions have a better chance of surviving. The main evolutionary process in all EAs is same and benchmark from the nature evolution: given an individual's population the environmental pressure causes natural selection by survival of the best so that it can cause a better situation for populations (best fitness value of the populations). Initially a population of the candidate of solutions is randomly created. Then they are evaluated by fitness function (that is equal or fit to objective function in optimization problem). Based on this fitness values some of the best candidates are selected and keep for make next generation by applying some operators such as recombination and mutation to them. Recombination operator is responsible to select and combine two or more candidates that are called parents in the step and generate new candidates (the children). Mutation operator causes an old candidate change to new one by changing a bit internally. By implementing these operators lead to set of new candidate solutions (so-called offspring) that cause better fitness rather than old ones. This process has to iterate until sufficient quality of fitness function is reached by new candidate solutions. Fig. 3 is a pseudo-code that shows general schemes of any EA.

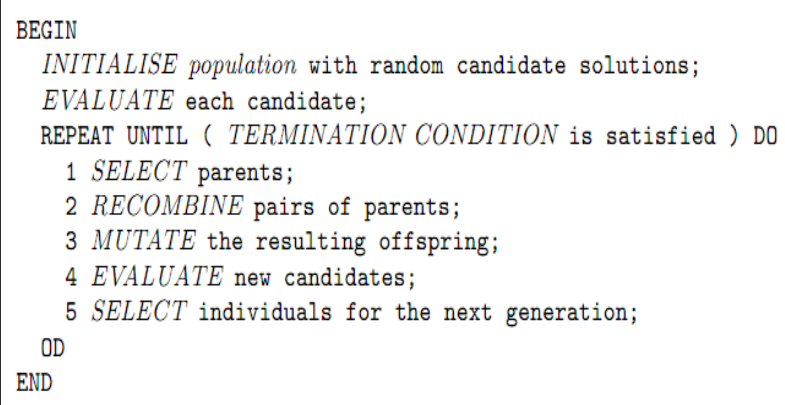

Fig. 3. General schemes of evolutionary algorithms

The usage of Darwinian principles for automated problem solving in early 1950 s resulted in the advent of evolutionary computing techniques [58]. Genetic algorithm (GA) that is the most popular EA is inspired from Darwinian principles and mimics the process of natural evolution is proposed by Holland [59]. Other algorithm in the sub-branch of meta-heuristic algorithms are evolutionary programming (EP) [60] and Differential Evolution Algorithm (DEA) [61]. In continue, evolutionary algorithm brief introduction and applications will be discussed. In the next we will explain just genetic algorithm as the most popular evolutionary algorithm and its application in GrSC activities. Recently Mondal et al. [62] used GSA to minimize the emission of nitrogen oxides and fuel consumption. Although this paper is in the field of load dispatch, but the same idea can be used to minimize fuel consumption and carbon emission in logistics network in GrSC.

\section{A. Genetic Algorithm}

Genetic Algorithm (GA) that is proposed by Holland in 
1975 [59]is an evolutionary and adaptive search method. GA mimics the mechanics of natural selection and evaluation. In any evolutionary process, only the most suited elements in a population (a set of solutions) are to survive and generate offspring, thus transmitting biological heredity to the new generations. In a similar way, GA also starts with a particular initial population and subsequent generations are created using generic operators. Population is a set of strings, each representing a potential solution to the given problem. Each string is called a chromosome and the elements of the chromosome are called genes. For creating the offspring only a promising string is selected so that the generic material is transferred effectively. Generic operators' are applied to the mating pool to create offspring. The set of strings chosen to create offspring is called mating pool. After the creation of a new set of strings, the population is evaluated and only the best elements are chosen for the next generation and finally the search ends with a best possible set of solutions. As Fig. 3 shows the structure of a simple GA, it would involve the following stages:

1) Representation of feasible solution to the problem as chromosomes and generation of the initial population.

2) Evaluation of the population using fitness function.

3) Generation of new population using the generic operators: Crossover (swaps a portion of the two parent chromosomes of the mating pool to create two new chromosomes); Mutation (select two random genes and then exchange their positions); Selection (select the best solutions).

4) Selection of new population using the offspring generated.

GA is a one the most popular EA that is implemented by scholars to optimize hard combinatorial problems and GrSC problems. Several authors have shown the effectiveness of using GA for reverse and closed-loop logistics network optimization and facility location optimization to lead supply chain to be green. Zarei et al. [63] designed an effective reverse logistics to collect and recycle end-of-life vehicles (ELVs) and they expressed due to model complexity GA can be used to solve and optimize the problem. In addition, GA applied has been applied for recovery and reverse logistics optimization for green suitcase chain [64], white goods industry [65] and product return in online sale networks [66]. Due to the influence of the reverse logistics activities on forward logistics such as occupancy of warehouse and transportation capacity, researchers have interested to integrate forward and reverse logistics to avoid sub-optimality [67]. In this regards closed-loop supply chain design has been more interested by researchers recently. However they are more complex comparing to forwards and reverse logistics solely. It caused GA has been applied in closed-loop supply chain in so many researches and fields. Kannan et al. [68] developed a close-loop supply chain for battery recycling and used GA and GAMS as solving approach. They compared results obtained by GAMS and GA and concluded the GA and GAMS results are close together for small size problems and when the problem would be equal as real case GAMS need more computational time. Mitra [69] has employed GA in inventory management in a deterministic and stochastic closed-loop supply chain. In the same studies, GA has been used for clopped-loop optimization as a solution approach [4], [34], [70], [71] and it is employed to overcome the complexity in forward and reverse integration problems in [72]-[74]. In some studies [75]-[77] such as researchers integrate GA approach with fuzzy theory to overcome uncertainty and some parameter fuzziness. GA has been used by researchers to optimize remanufacturing optimization such McGovern and Gupta [78] that minimize workstations, and ensures similar idle times, as well as other end-of-life specific concerns for balancing in a disassembly line. In the same light, GA has been employed in field of balancing disassembly lines and remanufacturing [79]-[81]. Recently, Li et al [82] designed a multi-objective model in reverse logistics to optimize cost and service level simultaneously. They used non-dominated sorting GA (NSAG2) method that has been developed by Deb et al. [83]. They can simultaneously address a set of possible solutions in one single run in reasonable time.

\section{Other MetA-HeUristic AlgORITHM}

Besides EAs and SIs algorithms, there are some other meta-heuristics algorithms that are inspired natural processes and events such as simulated annealing (SA) algorithm and Tabu search (TS). The SA's main idea is inspired from annealing technique in metallurgy [84]. It involves heating and controlled cooling to maximize the size of its crystals and minimize their defects. This notion of slow cooling is implemented with the SA algorithm as a slow decrease in the probability of accepting worse solutions as it explores the solution space. Pishvaee et al. developed a mixed integer linear programming model for transportation and opening cost in multistage reverse logistics and applied the SA algorithm to optimal solution. In another research Lee et al. [85] used SA to solve two-stage stochastic programming multi-period reverse logistics network model. Also in closed-loop supply chain problems SA algorithm has been employed by [4] that simulate bottles distilling/sale company in Korea. This paper designed the method of calculation for a solution using optimization algorithms with the priority-based genetic algorithm (priGA) and compared with $\mathrm{SA}$ result. Gu and Sosale [86] proposed an integrated modular design methodology for reusable, recyclable or remanufacturing products in life cycle engineering. They used SA algorithm for module formation and cluster the components. In GrSC multi-objective problems, multi-objective simulated annealing (MOSA) that proposed by Ulungu et al. [87] can be implemented.

Another meta-heuristic algorithm that is formulated by Glover [88], [89] is Tabu Search. TS algorithm is a local search method used for mathematical optimization. TS algorithm checks immediate neighbors in solution space in hope to find an improved solution. SA search and TS methods usually implement one move at each iteration, while genetic methods like GA may generate several new moves (individuals) at each iteration (generation) [90]. Many researchers prefer to employ $\mathrm{TS}$ as an effective method to solve mathematical models especially in the field of reverse and closed-loop logistics in GrSC problems such as [67], [91]-[94]. Furthermore, a recycle paper network has been optimized by 
Schweiger and Sahamie [95] and they used a hybrid TS for solving the model.

\section{CONCLUSION}

In this paper we have discussed on nature-based meta-heuristic algorithms that have been used in GrSC activities. We briefly reviewed kind of activities that should be considered in the supply chain to be green. Typical illustrations are addressed for PSO, ACO, ABC, GSA, GA, TA and SA algorithms, and their applications. A general overview of the state-of-the-art meta-heuristic algorithms in GrSC helps readers to refer proper algorithm in the practical solution in their models in the field. Some of our findings are listed in following:

1) Considering more variable in models to be more similar to the real world and multi-objective optimization instead of single objective to satisfy not only economic goals but also environmental and social objectives, cause GrSC to be complex problems. So that most of these models belong to the NP-hard class. Thus, heuristics and meta-heuristics algorithms are more interesting to be used by researchers in the last decade due to their abilities to find the optimal solution in reasonable computation time

2) The next achievement of this paper is that the number of researches on nature-inspired optimization algorithms for GrSC problems has increased significantly especially after 2000s.

3) Simulation nature-based ideas such as: mutations, recombination and reproduction are well suited for solving complex optimization problems like GrSC issues.

4) An algorithm may solve some problems better and some problems worse than others. Hence, so a proper algorithm should be selected regarding to the problem characteristics, available time for implementation of the model, computational requirement, and required solution quality.

Although GA has been used in a large percentage of early works, PSO and GSA and other swarm-based algorithms have gained more attention of scholars and practitioners since 2005.

\section{ACKNOWLEDGMENT}

This work received financial support from Ministry of Science, Technology and innovation of Malaysia under Research Project No. 5527085 and supported by the Institute of Advance Technology of University Putra Malaysia and gratefully acknowledged.

\section{REFERENCES}

[1] A. McWilliams and D. Siegel, "Corporate social responsibility and financial performance: correlation or misspecification?," Strategic Management Journal, vol. 21, pp. 603-609, 2000.

[2] S. K. Srivastava, "Green supply-chain management: A state-of-the-art literature review," International Journal of Management Reviews, vol. 9, pp. 53-80, 2007.

[3] A. Xanthopoulos and E. Iakovou, "On the optimal design of the disassembly and recovery processes," Waste Management, vol. 29, pp. 1702-1711, 2009.

[4] J. E. Lee and K. D. Lee, "Integrated forward and reverse logistics model: A case study in distilling and sale company in Korea,"
International Journal of Innovative Computing, Information and Control, vol. 8, pp. 4483-4495, 2012.

[5] G. Nenes and Y. Nikolaidis, "A multi-period model for managing used product returns," International Journal of Production Research, vol. 50, pp. 1360-1376, 2012.

[6] F. Wang, X. Lai, and N. Shi, "A multi-objective optimization for green supply chain network design," Decision Support Systems, vol. 51, pp. 262-269, 2011.

[7] J. Mostard and R. Teunter, "The newsboy problem with resalable returns: A single period model and case study," European journal of operational research, vol. 169, pp. 81-96, 2006.

[8] S. Kumar and T. Yamaoka, "System dynamics study of the Japanese automotive industry closed loop supply chain," Journal of Manufacturing Technology Management, vol. 18, pp. 115-138, 2007.

[9] D. Vlachos, P. Georgiadis, and E. Iakovou, "A system dynamics model for dynamic capacity planning of remanufacturing in closed-loop supply chains," Computers \&amp; Operations Research, vol. 34, pp. 367-394, 2007.

[10] J. P. Kenne, P. Dejax, and A. Gharbi, "Production planning of a hybrid manufacturingremanufacturing system under uncertainty within a closed-loop supply chain," International Journal of Production Economics, vol. 135, pp. 81-93, 2012.

[11] N.-B. Chang and S. F. Wang, "A fuzzy goal programming approach for the optimal planning of metropolitan solid waste management systems," European journal of operational research, vol. 99, pp. 303-321, 1997.

[12] A. Amiri, "Designing a distribution network in a supply chain system: Formulation and efficient solution procedure," European journal of operational research, vol. 171, pp. 567-576, 2006.

[13] M. Dorigo, M. Birattari, and T. Stutzle, "Ant colony optimization," Computational Intelligence Magazine, IEEE, vol. 1, pp. 28-39, 2006.

[14] M. S. Pishvaee and S. A. Torabi, "A possibilistic programming approach for closed-loop supply chain network design under uncertainty," Fuzzy Sets and Systems, vol. 161, pp. 2668-2683, 2010.

[15] E. Rashedi, H. Nezamabadi-pour, and S. Saryazdi, "GSA: a gravitational search algorithm," Information Sciences, vol. 179, pp. 2232-2248, 2009.

[16] D. H. Wolpert and W. G. Macready, "No free lunch theorems for optimization," Evolutionary Computation, IEEE Transactions on, vol. 1, pp. 67-82, 1997.

[17] B. L. Partridge, "The structure and function of fish schools," Scientific American, vol. 246, pp. 114-123, 1982.

[18] H. Dyke Parunak and S. Brueckner, "Engineering swarming systems," Methodologies and Software Engineering for Agent Systems, pp. 341-376, 2004.

[19] M. Dorigo and G. Di Caro, "Ant colony optimization: a new meta-heuristic," 1999.

[20] M. Dorigo and T. Stützle, "The ant colony optimization metaheuristic: Algorithms, applications, and advances," Handbook of metaheuristics, pp. 250-285, 2003.

[21] J. Kennedy and R. Eberhart, "Particle swarm optimization," 1995, pp. 1942-1948 vol. 4.

[22] D. Karaboga and B. Basturk, "A powerful and efficient algorithm for numerical function optimization: artificial bee colony (ABC) algorithm," Journal of Global Optimization, vol. 39, pp. 459-471, 2007.

[23] D. Karaboga and B. Basturk, "Artificial bee colony (ABC) optimization algorithm for solving constrained optimization problems," Foundations of Fuzzy Logic and Soft Computing, pp. 789-798, 2007.

[24] E. Rashedi, H. Nezamabadi-Pour, and S. Saryazdi, "BGSA: binary gravitational search algorithm," Natural Computing, vol. 9, pp. 727-745, 2009.

[25] A. H. Gandomi and A. H. Alavi, "Krill herd: A new bio-inspired optimization algorithm," Communications in Nonlinear Science and Numerical Simulation, vol. 17, pp. 4831-4845, 2012.

[26] H. Shah-Hosseini, "The intelligent water drops algorithm: a nature-inspired swarm-based optimization algorithm," International Journal of Bio-Inspired Computation, vol. 1, pp. 71-79, 2009.

[27] R. Poli, J. Kennedy, and T. Blackwell, "Particle swarm optimization," Swarm intelligence, vol. 1, pp. 33-57, 2007.

[28] S. Dehuri and S. Cho, "Theoretical foundations of knowledge mining and intelligent agent," Knowledge Mining Using Intelligent Agents, vol. 6, pp. 1, 2010.

[29] Y. Shi, "Particle swarm optimization: developments, applications and resources," 2001, pp. 81-86.

[30] Q. Zhu, L. Qian, Y. Li, and S. Zhu, "An improved particle swarm optimization algorithm for vehicle routing problem with time windows," 2006, pp. 1386-1390. 
[31] B. F. Moghaddam, R. Ruiz, and S. J. Sadjadi, "Vehicle routing problem with uncertain demands: An advanced particle swarm algorithm," Computers \&amp; Industrial Engineering, vol. 62, pp. 306-317, 2012.

[32] L. Nan, "Research on location of remanufacturing factory based on particle swarm optimization," in Proc. 2011 International Conference on Management Science and Industrial Engineering (MSIE), 2011, pp. 1016-1019.

[33] L. Yanchao, L. Xiaoyan, and L. Litao, "Multi-objective optimization of reverse logistics network based on improved particle swarm optimization," in Proc. 7th World Congress on Intelligent Control and Automation, WCICA 2008., 2008, pp. 7476-7480.

[34] G. Kannan, A. N. Haq, and M. Devika, "Analysis of closed loop supply chain using genetic algorithm and particle swarm optimisation," International Journal of Production Research, vol. 47, pp. 1175-1200, 2009.

[35] H. R. Hassanzadeh and M. Rouhani, "A Multi-objective Gravitational Search Algorithm," in Proc. Computational Intelligence, Communication Systems and Networks (CICSyN), 2010 Second International Conference on, 2010, pp. 7-12.

[36] X. Li, "Better spread and convergence: Particle swarm multiobjective optimization using the maximin fitness function," in Proc. Genetic and Evolutionary Computation-GECCO 2004, 2004, pp. 117-128.

[37] X. Li, "A non-dominated sorting particle swarm optimizer for multiobjective optimization," in Proc. Genetic and Evolutionary Computation-GECCO 2003, 2003, pp. 198-198.

[38] X. Liu, W. Jiang, and J. Xie, "Vehicle routing problem with time windows: a hybrid particle swarm optimization approach," in Proc. Natural Computation, 2009. ICNC'09. Fifth International Conference on, 2009, pp. 502-506.

[39] S. Masrom, S. Z. Z. Abidin, A. Nasir, and A. Rahman, "Hybrid particle swarm optimization for vehicle routing problem with time windows," in Proceedings of the 13th WSEAS international conference on mathematical methods, computational techniques and intelligent systems, and 10th WSEAS international conference on non-linear analysis, non-linear systems and chaos, and 7th WSEAS international conference on dynamical systems and control, and 11th WSEAS international conference on Wavelet analysis and multirate systems: recent researches in computational techniques, non-linear systems and control, 2011, pp. 142-147.

[40] W. Jiang, Y. Zhang, and J. Xie, "A particle swarm optimization algorithm with crossover for vehicle routing problem with time windows," in Proc. Computational Intelligence in Scheduling, IEEE Symposium on, 2009, pp. 103-106.

[41] M. Dorigo, "Optimization, learning and natural algorithms," Ph. D. Thesis, Politecnico di Milano, Italy, 1992.

[42] R. Beckers, J. L. Deneubourg, and S. Goss, "Trails and U-turns in the selection of a path by the ant Lasius niger," Journal of theoretical biology, vol. 159, pp. 397-415, 1992.

[43] L. A. Moncayo-Martínez and D. Zhang, "Pareto ant colony optimisation: a meta-heuristic approach to supply chain design," 2007

[44] S. McGovern and S. Gupta, "Ant colony optimization for disassembly sequencing with multiple objectives," The International Journal of Advanced Manufacturing Technology, vol. 30, pp. 481-496, 2006.

[45] L.-P. Ding, Y.-X. Feng, J.-R. Tan, and Y.-C. Gao, "A new multi-objective ant colony algorithm for solving the disassembly line balancing problem," The International Journal of Advanced Manufacturing Technology, vol. 48, pp. 761-771, 2010.

[46] A. V. Donati, R. Montemanni, N. Casagrande, A. E. Rizzoli, and L. M. Gambardella, "Time dependent vehicle routing problem with a multi ant colony system," European journal of operational research, vol. 185, pp. 1174-1191, 2008.

[47] L. M. Gambardella, A. E. Rizzoli, F. Oliverio, N. Casagrande, A. Donati, R. Montemanni, and E. Lucibello, "Ant Colony Optimization for vehicle routing in advanced logistics systems," 2003, pp. 3-9.

[48] J. Bautista, E. Fernandez, and J. Pereira, "Solving an urban waste collection problem using ants heuristics," Computers \&amp; Operations Research, vol. 35, pp. 3020-3033, 2008.

[49] V. M. C. Esteves, J. M. C. Sousa, C. A. Silva, A. P. B. PÃ ${ }^{3}$ voa, and M. I. Gomes, "SCant-design: Closed loop supply chain design using ant colony optimization," in Proc. 2012 IEEE Congress on Evolutionary Computation, CEC 2012, 2012.

[50] D. Karaboga, "An idea based on honey bee swarm for numerical optimization," Techn. Rep. TR06, Erciyes Univ. Press, Erciyes, 2005.

[51] D. Teodorovic and M. DellOrco, "Bee colony optimization a cooperative learning approach to complex transportation problems," in Advanced OR and AI Methods in Transportation: Proceedings of 16th Mini EURO Conference and 10th Meeting of EWGT (13-16 September 2005), Poznan: Publishing House of the Polish Operational and System Research, 2005, pp. 51-60.
[52] V. K. Vishwa, F. T. S. Chan, N. Mishra, and V. Kumar "Environmental integrated closed loop logistics model: An artificial bee colony approach," in Proc. Supply Chain Management and Information Systems (SCMIS), 2010 8th International Conference on, 2010, pp. 1-7.

[53] B. Xing, W.-J. Gao, F. Nelwamondo, K. Battle, T. Marwala, Y. Tan, Y. Shi, and Z. Ji, "Swarm Intelligence Supported e-Remanufacturing Advances in Swarm Intelligence." vol. 7331, ed: Springer Berlin Heidelberg, 2012, pp. 45-52.

[54] S. Banerjee, G. Dangayach, S. Mukherjee, and P. Mohanti, "Modelling process and supply chain scheduling using hybrid meta-heuristics," Metaheuristics for scheduling in industrial and manufacturing applications, pp. 277-300, 2008.

[55] C. Li and J. Zhou, "Parameters identification of hydraulic turbine governing system using improved gravitational search algorithm," Energy Conversion and Management, vol. 52, pp. 374-381, 2011.

[56] A. Sadrnia, H. Nezamabadi-Pour, M. Nikbakht, and N. Ismail, "A Gravitational Search Algorithm Approach for Optimizing Closed-Loop Logistics Network," in Meta-Heuristics Optimization Algorithms in Engineering, Business, Economics, and Finance, ed: IGI Global, 2012, pp. 616-638.

[57] M. Ojha, K. Deep, A. Nagar, M. Pant, and J. C. Bansal, "Optimizing Supply Chain Management Using Gravitational Search Algorithm and Multi Agent System. Proceedings of the International Conference on Soft Computing for Problem Solving (SocProS 2011) December 20-22, 2011." vol. 130, ed: Springer Berlin / Heidelberg, 2012, pp. 481-491.

[58] S. Das, S. Maity, B. Y. Qu, and P. Suganthan, "Real-parameter evolutionary multimodal optimization--a survey of the state-of-the-art," Swarm and Evolutionary Computation, 2011.

[59] J. Holland, "Adaptation in Natural and Artificial Systems: An Introductory Analysis with Applications to Biology," Control, and Artificial Intelligence (MIT Press, Cambridge, MA, 1992), 1975.

[60] L. Fogel, A. J. Owens, and M. J. Walsh, Artificial Intelligence through Simulated Evolution: Wiley, 1966.

[61] R. Storn, "On the usage of differential evolution for function optimization," in Fuzzy Information Processing Society, 1996. NAFIPS. 1996 Biennial Conference of the North American, 1996, pp. 519-523.

[62] S. Mondal, A. Bhattacharya, and S. H. nee Dey, "Multi-objective economic emission load dispatch solution using gravitational search algorithm and considering wind power penetration," International Journal of Electrical Power \&amp; Energy Systems, vol. 44, pp. 282-292, 2013.

[63] M. Zarei, S. Mansour, A. Husseinzadeh Kashan, and B. Karimi, "Designing a Reverse Logistics Network for End-of-Life Vehicles Recovery," Mathematical Problems in Engineering, vol. 2010, 2010.

[64] C. F. Tsai, "A grey genetic algorithm for uncertainty reverse logistics," in Proceedings of the 2012 IEEE 16th International Conference on Computer Supported Cooperative Work in Design, CSCWD 2012, 2012, pp. 885-892.

[65] G. Tuzkaya, B. Gülsün, and Ş. Önsel, "A methodology for the strategic design of reverse logistics networks and its application in the Turkish white goods industry," International Journal of Production Research, vol. 49, pp. 4543-4571, 2012/06/24 2011

[66] H. Min, H. Jeung Ko, and C. Seong Ko, "A genetic algorithm approach to developing the multi-echelon reverse logistics network for product returns," Omega, vol. 34, pp. 56-69, 2004.

[67] D. H. Lee and M. Dong, "A heuristic approach to logistics network design for end-of-lease computer products recovery," Transportation Research Part E: Logistics and Transportation Review, vol. 44, pp. 455-474, 2008.

[68] G. Kannan, P. Sasikumar, and K. Devika, "A genetic algorithm approach for solving a closed loop supply chain model: A case of battery recycling," Applied Mathematical Modelling, vol. 34, pp. 655-670, 2010.

[69] S. Mitra, "Inventory management in a two-echelon closed-loop supply chain with correlated demands and returns," Computers and Industrial Engineering, vol. 62, pp. 870-879, 2011.

[70] H. Min, C. S. Ko, and H. J. Ko, "The spatial and temporal consolidation of returned products in a closed-loop supply chain network," Computers and Industrial Engineering, vol. 51, pp. 309-320, 2006.

[71] H. F. Wang and H. W. Hsu, "A closed-loop logistic model with a spanning-tree based genetic algorithm," Computers \& Operations Research, vol. 37, pp. 376-389, 2009.

[72] D. H. Lee, W. Bian, and M. Dong, "Multiobjective model and solution method for integrated forward and reverse logistics network design for third-party logistics providers," Transportation Research Record, 2007, pp. 43-52.

[73] Y. Dai, Z. J. Ma, and F. Liu, "Optimal design of integrated logistics networks for manufacturing/remanufacturing systems based on hybrid genetic algorithm," Jisuanji Jicheng Zhizao Xitong/Computer 
Integrated Manufacturing Systems, CIMS, vol. 12, pp. $1853-1859+1875,2006$.

[74] H. J. Ko and G. W. Evans, "A genetic algorithm-based heuristic for the dynamic integrated forward/reverse logistics network for 3PLs," Computers \& Operations Research, vol. 34, pp. 346-366, 2007.

[75] Z. Qin and X. Ji, "Logistics network design for product recovery in fuzzy environment," European journal of operational research, vol. 202, pp. 479-490, 2009.

[76] L. K. Chu, Y. Shi, S. Lin, D. Sculli, and J. Ni, "Fuzzy chance-constrained programming model for a multi-echelon reverse logistics network for household appliances," Journal of the operational research society, vol. 61, pp. 551-560, 2010.

[77] X. Zhou and J. Xu, "A class of integrated logistics network model under random fuzzy environment and its application to chinese beer company," International Journal of Uncertainty, Fuzziness and Knowlege-Based Systems, vol. 17, pp. 807-831, 2009.

[78] S. M. McGovern and S. M. Gupta, "A balancing method and genetic algorithm for disassembly line balancing," European journal of operational research, vol. 179, pp. 692-708, 2007.

[79] Y. Li, J. Chen, and X. Cai, "Heuristic genetic algorithm for capacitated production planning problems with batch processing and remanufacturing," International Journal of Production Economics, vol. 105, pp. 301-317, 2007.

[80] E. Kongar and S. M. Gupta, "Disassembly sequencing using genetic algorithm," The International Journal of Advanced Manufacturing Technology, vol. 30, pp. 497-506, 2006.

[81] C. Lim and E. Sim, "Production planning in manufacturing/remanufacturing environment using genetic algorithm," in Proceedings of the 2005 conference on Genetic and evolutionary computation, 2005, pp. 2217-2218.

[82] S. Li, N. Wang, Z. He, A. Che, and Y. Ma, "Design of a Multiobjective Reverse Logistics Network Considering the Cost and Service Level," Mathematical Problems in Engineering, vol. 2012, p. 21, 2012.

[83] K. Deb, A. Pratap, S. Agarwal, and T. Meyarivan, "A fast and elitist multiobjective genetic algorithm: NSGA-II," IEEE Transactions on Evolutionary Computation, , vol. 6, pp. 182-197, 2002.

[84] S. Kirkpatrick, C. D. Gelatt, and M. P. Vecchi, "Optimization by Simulated Annealing," Science, vol. 4598, pp. 671-680, 1983.

[85] D.-H. Lee and M. Dong, "Dynamic network design for reverse logistics operations under uncertainty," Transportation Research Part E: Logistics and Transportation Review, vol. 45, pp. 61-71, 2009.

[86] P. Gu and S. Sosale, "Product modularization for life cycle engineering," Robotics and Computer-Integrated Manufacturing, vol. 15, pp. 387-401, 1999.

[87] E. L. Ulungu, J. Teghem, P. H. Fortemps, and D. Tuyttens, "MOSA method: a tool for solving multiobjective combinatorial optimization problems," Journal of Multi-Criteria Decision Analysis, vol. 8, pp. 221-236, 1999.

[88] F. Glover, "Tabu search—part II," ORSA Journal on computing, vol. 2 , pp. 4-32, 1990

[89] F. Glover, "Tabu search—part I," ORSA Journal on computing, vol. 1, pp. 190-206, 1989

[90] T. G. Crainic and M. Toulouse, "Parallel Meta-heuristics," Handbook of metaheuristics, pp. 497-541, 2010.

[91] F. Schultmann, M. Zumkeller, and O. Rentz, "Modeling reverse logistic tasks within closed-loop supply chains: An example from the automotive industry," European journal of operational research, vol. 171, pp. 1033-1050, 2006.

[92] N. Aras, D. Aksen, and A. Gonul Tanugur, "Locating collection centers for incentive-dependent returns under a pick-up policy with capacitated vehicles," European journal of operational research, vol. 191, pp. 1223-1240, 2008.

[93] J. Li and Q. Da, "Multiple vehicle routing problem integrated reverse logistics with fuzzy reverse demands," Journal of Southeast University (English Edition), vol. 24, pp. 222-227, 2008.

[94] M. S. Pishvaee, K. Kianfar, and B. Karimi, "Reverse logistics network design using simulated annealing," The International Journal of Advanced Manufacturing Technology, vol. 47, pp. 269-281, 2009.

[95] K. Schweiger and R. Sahamie, "A hybrid Tabu Search approach for the design of a paper recycling network," Transportation Research Part E: Logistics and Transportation Review, vol. 50, p. 98.

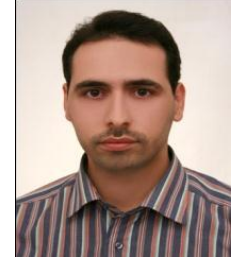

Abdolhossein Sadrnia is an industrial engineering $\mathrm{PhD}$ candidate in the Department of Mechanical and Manufacturing Engineering, Faculty of Engineering, University of Putra Malaysia (UPM). He holds a Master of Science in the Industrial Engineering from Sharif University of Technology. His major current research interests are focused on green supply chain and closed-loop supply chain as well as meta-heuristics algorithm application to optimize logistics network. His papers have been presented in the several international conferences.

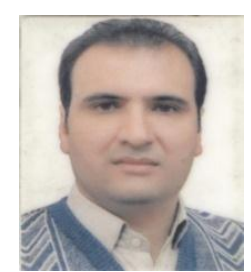

Hamid Reza Soltani is doing his Ph.D. in the department of Mechanical and Manufacturing Engineering, University of Putra Malaysia (UPM), Malaysia. He received his bachelor degree in Textile Engineering from Amir Kabir University (Politechnic Tehran), Iran, 2000; his Master degree in Manufacturing System Engineering from Universiti Putra Malaysia in 2011; and now, he is preparing his doctoral thesis. He has more than 5 research papers in the fields of her research interests; exact, heuristic and meta-heuristic algorithms, manufacturing systems, fuzzy logic and decision support systems.

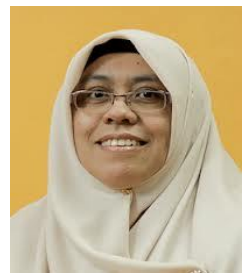

Norzima Zulkifli is currently a doctor and lecturer at Universiti Putra Malaysia (UPM); she is the Graduate Member in Institution of Engineers (IEM), Malaysia. She obtained her Bachelor degree in Industrial Engineering from University of Alabama USA; his Master degree in Quality Management from University of Sunderland, UK; and his Doctorate degree in Manufacturing Engineering from Universiti Kebangsaan Malaysia (UKM). Her main domain of interest concerns the Industrial Engineering, Quality Management, Manufacturing Management, Small and Medium Industries.

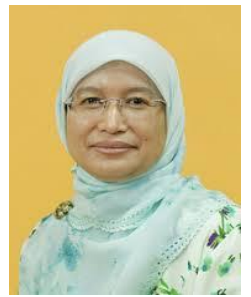

Napsiah Ismail is a professor in the field of Manufacturing Engineering in University of Putra Malaysia (UPM), Malaysia. She received Bachelor degree in Production Engineering, Leeds Metropolitan University (LMU), UK, master in the Mechanical from LMU, and doctoral degree in Mechanical from Universiti Teknologi Malaysia (UTM), Malaysia. She has over 40 research papers. Her research interest includes simulation and scheduling for flexible manufacturing systems, advance factory automations and industrial strategy settings.

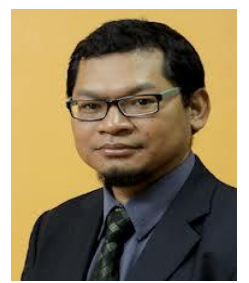

Mohd Khairol Anuar Mohd Ariffin is an associate professor in the field of Manufacturing Engineering in University of Putra Malaysia (UPM), Malaysia. $\mathrm{He}$ received Bachelor degree in Manufacturing System Engineering, Northumbria University, UK, Master in Manufacturing Engineering from Universiti Putra Malaysia (UPM), and doctora degree in Manufacturing Engineering from University of Sheffield, UK. He has over 30 research papers. His research interest includes optimisation, advanced manufacturing technology, automation and robotics, CAD/CAM. 